\title{
The Swedish experience in the organisation of domiciliary ventilation for patients with a high spinal cord injury ${ }^{1}$
}

\author{
R Harlid MD, G Andersson MD \\ Respiratory Unit, Department of Anaesthesia and Intensive Care, Danderyd Hospital, \\ Danderyd, Sweden.
}

Keywords: traumatic tetraplegia; domiciliary ventilation.

The Respiratory Unit at Danderyd Hospital mainly serves the Stockholm area with a population of 1.2 million people. Patients with special respiratory difficulties, however, can be sent to us from other parts of Sweden, especially since 1989 when we were appointed the national specialist clinic by the Swedish Medical Board. An explanation will be given concerning the incidence of high tetraplegia, the present and future medical and economic situation, and finally the author's own experiences concerning patients with high spinal lesions requiring assisted ventilation.

It has been very difficult to find figures of the total incidence of cervical spinal cord injuries as autopsy reports do not often focus on this particular diagnosis as a cause of death. Of survivors that I have been in contact with, more than $50 \%$ had sufficient breathing during the initial period. The remainder, of course, were dependent on people being available for rescuing interventions. Sweden is a long country with a wide road network and a low traffic density, a long coast, more than 100,000 lakes and an archipelago of more than 60,000 islands. The beaches are not guarded and we have few road patrols. This together with a low population density probably has a negative influence on the survival rate in traumatic injuries.

There has been an attempt to evaluate the incidence and severity of spinal cord lesions using the Frankel classification of grade of incompleteness. There are approximately

\footnotetext{
${ }^{1}$ Paper read at the First European Conference on Domiciliary Ventilation and High Spinal Cord Lesion in Southport, England, in October 1991.
}

120 patients or 15 per million inhabitants each year registered with a spinal cord lesion of Frankel grade A, B. This means patients with no motor nerve function or no nerve function at all below the injury level. Of these, 5 per million per year have cervical cord lesions. If one adds cervical cord lesions of Frankel grade $\mathrm{C}$, the total of $\mathrm{A}+\mathrm{B}+\mathrm{C}$ (that means with no useful voluntary motor activity) the incidence will be close to $7 /$ million/year. There are no figures, however, of how many of these patients are ventilator dependent but a qualified guess is that we have less than $1 /$ million/year in Sweden. That means 5-8 persons annually with this severe condition.

The patient is usually either in, or is immediately taken to a neurosurgical clinic. There are five of these in Sweden, all fairly similar in quality. Due to the great pressure upon them the patient will be moved to some other clinic as soon as possible. For patients with ventilator dependency the natural place is an intensive care unit, as there are almost no other wards capable of handling a patient requiring a ventilator. There are no centres for high spinal cord lesions in combination with respiratory insufficiency, but a few clinics have considerable experience in dealing with patients with spinal cord lesions. The community tax system will, however, usually favour geographic proximity and patients will in this way be scattered all over Sweden in smaller or larger hospitals.

The stay in the intensive care unit may become very long, probably longer than really necessary. The patient will be a victim of multidisciplinary interest, especially at the beginning, because of associated problems. Not infrequently have I been able to 
count more than a dozen different clinics being involved in the care of the patient. There are so many unique problems of a medical, psychological, financial, political and social nature that the present situation must be regarded as quite unsatisfactory. There is presently an investigation by an expert group put together by the Swedish Medical Board into how to improve this situation. The main question seems to be how many spinal centres should there be. One suggestion is to regionalise the care to five or six centres with good access to neurosurgical expertise. Some experts advocate that there has to be at least 30 new cases annually in order to create an effective centre. This would mean two or three centres in Sweden. Geographically that means that the patient may be treated far away from family and friends, but the need for specialist care will have to take priority. There seems to be a majority in favour of the second solution, including those involved in patients' organisations. Once the patient has returned home the doctors in immediate charge can contact these centres if necessary, and the patient should also go there routinely, regularly, at least once a year for check-ups.

In the present situation work therapists will equip the patient with a personally tailoured outfit during the hospital stay to suit his or her special needs. This usually includes an ordinary and an electrically manouvered wheelchair. It also often includes some form of computerised communication system, which eventually can be used for study, work and controlling the surroundings eg TV, radio, telephone, modem, the wheelchair and other functions. The Respiratory Unit, where I work, takes responsibility for the respiration-related problems of patients sent to us. We arrange for suitable ventilators, suction devices, a phrenic nerve stimulator if possible and a tailor made tracheal cannula.

When the patient is ready to move out from the hospital, the home and possibly also the workplace will have to be adjusted to his or her special needs and personnel will have to be employed. The need for help will be evaluated by the community. It can be given up to 24 hours daily and a new evaluation will be made every 6 months. The personnel can be found and employed directly by the community. There is also a relatively new system called STIL where the patient is the employer but receives money from the community. A relative can be paid up to $£ 300$ per month for care.

Different parts of the social security net will provide equipment, depending on its function. All in all the community has a comparatively liberal view on the costs of rehabilitation and the patient will be well equipped. Unfortunately, however, it takes a great effort by the patient, relatives and special personnel to find ways through the political and economic jungle. During 3 years in the Respiratory Unit I have come in contact with 20 ventilator dependent patients with high spinal cord lesions. Out of these 20 patients we have worked most extensively with 16 . Nine of the patients were women and 11 men. During this time one woman died. The mean age of the patients was 29 years ranging from 6-69, and mean treatment time 8 years ranging from 1-39. The cause of injury was traffic accidents (9), diving (2), children's play (1), work (1), tumours (2) and spinal abscess (1). Seventeen of the patients have been able to move home. Six are working or studying.

In Sweden the interest in and experiences of phrenic nerve stimulation is mainly confined to one neurosurgeon, who has performed $90 \%$ of the operations. There are approximately 25 persons who have had phrenic nerve stimulators implanted. In our group 15 have this device and 11 are able to use it. The mean treatment time was 6 years, ranging from 1 to 12. As this neurosurgeon no longer works in Sweden there is a potential danger that the few operations, maybe one or two annually, will be performed by different surgeons in different places and this would probably not be a very good arrangement.

We see most of our patients every 2 to 4 weeks in the Respiratory Unit. This gives us time to talk to them and to recognize both their medical and other special needs. It is therefore the firm belief of the author that we need a quick consensus on how to organise centralised care for these patients. 
The author would also welcome an interna- whom they could turn with problems when tional list of physicians and/or clinics to travelling. 